\title{
Fraud and hoaxes in science
}

\author{
William H. James
}

\section{The recent spate of moral condemnation of fraud in science reflects the conservative nature of scientists; fraud, like error, is a normal part of science and cannot be legislated away.}

I SHOULD like to offer some qualifications to the current crusade against scientific fraud. It seems to me that scientists are being po-faced. The metaphor of a few rotten apples (in a barrelful of sound ones) is deceptive: it implies that we may believe any paper that is not by a few identified fraudsters. I suggest that the overstrident urge to condemn scientific malpractice is due to the unadventurous nature of scientists today, and their failure to understand the nature of science - to appreciate that judgement is required in assessing the validity of scientific claims.

Scientists are selected by examinations that favour vertical over lateral thinking; they have to demonstrate their docility by learning the curriculum (nine-tenths of which is never used again); and they are encouraged to think in terms of career structures. Many are therefore deeply unwilling to accept that error is part of science and cannot be legislated away. This timidity is reminiscent of the widely held view that politicians should have blameless sex lives. The analogy appears in the question: "Otherwise, how can we trust them?" The minor answer (at least for scientists) is that it is seldom in their interests to lie: they are likely to be rumbled. The major answer is that trust should not be sought in science. It is a sign of the current intellectual malaise that it should be so widely yearned for. Scientists who need certainty should change their field to mathematics or logic. In a letter of 1817 , John Keats wrote: "it struck me what quality went to form a Man of Achievement especially in Literature and which Shakespeare possessed so enormously I mean Negative Capability that is when a man is capable of being in uncertainties, mysteries, doubts, without any irritable reaching after fact and reason". This applies to scientists of achievement too.

\section{Error detection}

I have little doubt that, if I chose, I could write and publish a paper plausibly claiming, say, that left-handed people have higher coital rates, on the average, than right-handers. The reader's job then is to assess the paper and decide what degree of belief to assign to the proposition rather than simply to refer to a list of dodgy authors. There is a whole array of skills that the reader should use to detect error. It is error that is important, not its cause; and error in science is far more common than outright fraud.
To concentrate on fraud is to overemphasize one (probably minor) cause of error. To detect error, the reader should ask whether I (the author of the hypothetical paper) am left-handed; whether I can reliably perform a Mann-Whitney test; whether I have devoted too much time to a hypothesis that is probably false; whether I am a fellow of All Souls or a student at the Tri-State College for SelfImprovement; whether left-handers are bigger liars than right-handers; whether I have used an unconventional definition of left-handedness; whether the coital rates were based on reported or recorded data; whether I am merely confirming the work of someone else (or making an original claim); and whether the $p$-value seems to be correctly assessed - and after all that, the reader should decide how much credence should be assigned to the paper. So why not add a query about fraud?

The scientific community should accommodate itself to the ineradicable presence of fraudsters. I am sceptical that fraud can be controlled, except by the prospect of being caught by subsequent researchers doing what Thomas Kuhn called "normal" science'. The willingness to commit fraud seems widespread. A recent paper ${ }^{2}$ reported that about a third of applicants for gastroenterology fellowships in the United States had misrepresented their academic accomplishments. The misrepresentation included citations of nonexistent articles in actual journals, articles in nonexistent journals and articles falsely identified as "in press". Among the recommendations of the authors were that "medical students and residents should be taught that embellishments of curricula vitae constitute misconduct". But such teaching would be redundant: those students knew that already.

Politics is often said to be about policies and not personalities. This is largely false. Similarly, it is wrong to think of science as a process independent of its practitioners. Scientists are people. Some are straightforward. Others are devious, confused, lazy, careless, psychotic, depressed, manic or the victims of domestic trouble.

Some scientists think of science as a game: we have to identify the rules by which they play. Some chessplayers are skilled in momentarily distracting their opponent's attention - and secretly rearranging the pieces. Some scientists are psychopaths: it is the business of other scientists to detect signs of this condition. We should learn to associate some of these traits with certain authors - and assess their papers accordingly.

Sir Cyril Burt was the most famous psychologist in the world. It now seems that he may have fabricated data to support an hypothesis he believed. Lionel Penrose is credited with remarking of a lecture given by Burt: "I greatly admire the way the old boy says it - but I don't believe a word of what he says!" Penrose's robustness in the face of possible fraud deserves admiration. We should be looking not for scientists we can trust to tell the truth, but for scientists who get it right (a criterion Burt now seems to meet).

\section{Risk motivation}

Scientists seem to lack curiosity about what drives fraudsters. There clearly are several motivations, some of which are, admittedly, reprehensible. The more squalid fraudsters simply want tenure, or more research funds, or easy money from drug companies. They merit contempt. But others (for whom one may have some sympathy) go to immense trouble to pull an elaborate hoax. I doubt whether the harm done by scientific hoaxers is commensurate with the fuss made about them. Whoever planted the Piltdown skull provided an interesting problem for others to unravel, a stimulus for further research and some entertainment.

When we have been hoaxed, excessive censure is unseemly. We are the victims of a practical joke: our amour propre has been disturbed. But we should be no more Victorian about it than, say, about adultery. Scientific fraud should be regarded as perhaps regrettable, but certainly an ineradicable, interesting and integral part of science.

James Watson has proposed ${ }^{3}$ a swashbuckling set of rules for success in science, one of which is a preparedness to take risks. Let us think of scientific hoaxers as merely overstepping the limits of such preparedness.

William H. James is in the Department of Genetics and Biometry, University College London, 4 Stephenson Way, London NW1 $2 H E$, UK.

\footnotetext{
1. Kuhn, T. The Structure of Scientific Revolutions (Univ. Chicago Press, 1962)

2. Sekas, G. \& Hutson, W. R. Ann. intern. Med. 123, 38 (1995).

3. Watson, J. D. Science 261, 1812 (1993)
} 